Article

\title{
Evaluation of TRMM/GPM Blended Daily Products over Brazil
}

\author{
José Roberto Rozante ${ }^{1, *(1)}$, Daniel A. Vila ${ }^{1}$ (D), Júlio Barboza Chiquetto ${ }^{2}$ (iD, \\ Alex de A. Fernandes ${ }^{1}$ and Débora Souza Alvim ${ }^{3}$ \\ 1 Center for Weather Forecast and Climate Studies, National Institute for Space Research, Rodovia Presidente \\ Dutra, Km 40, SP-RJ-CEP, Cachoeira Paulista, SP 12630-000, Brazil; daniel.vila@inpe.br (D.A.V.); \\ alex.fernandes@inpe.br (A.d.A.F.) \\ 2 Department of Geography, University of Sao Paulo (USP), São Paulo, SP 05508-080, Brazil; julio22@usp.br \\ 3 Center of Natural and Human Sciences (CCNH), Federal University of ABC (UFABC), Santo André, SP \\ 09210-580, Brazil; debora.alvim@ufabc.edu.br \\ * Correspondence: roberto.rozante@inpe.br; Tel.: +55-12-3208-8400
}

Received: 1 March 2018; Accepted: 11 April 2018; Published: 6 June 2018

\begin{abstract}
The precipitation estimates from the Tropical Rainfall Measuring Mission (TRMM) Multi-satellite Precipitation Analysis (named TMPA and TMPA-RT for the near real-time version) are widely used both in research and in operational forecasting. However, they will be discontinued soon. The products from the Integrated Multi-satellite Retrievals for Global Precipitation Measurement (IMERG) and The Global Satellite Mapping of Precipitation (GSMaP) are analyzed as potential replacements for TMPA products. The objective of this study is to assess whether the IMERG and/or GSMaP products can properly replace TMPA in several regions with different precipitation regimes within Brazil. The validation study was conducted during the period from 1st of April, 2014 to the 28th of February, 2017 (1065 days), using daily accumulated rain gauge stations over Brazil. Six regions were considered for this study: five according to the precipitation regime, plus another one for the entire Brazilian territory. IMERG-Final, TMPA-V7 and GSMaP-Gauges were the selected versions of those algorithms for this validation study, which include a bias adjustment with monthly (IMERG and TMPA) and daily (GSMaP) gauge accumulations, because they are widely used in the user's community. Results indicate similar behavior for IMERG and TMPA products, showing that they overestimate precipitation, while GSMaP tend to slightly underestimate the amount of rainfall in most of the analyzed regions. The exception is the northeastern coast of Brazil, where all products underestimate the daily rainfall accumulations. For all analyzed regions, GSMaP and IMERG products present a better performance compared to TMPA products; therefore, they could be suitable replacements for the TMPA. This is particularly important for hydrological forecasting in small river basins, since those products present a finer spatial and temporal resolution compared with TMPA.
\end{abstract}

Keywords: precipitation; satellite; GPM

\section{Introduction}

Knowledge of the spatial and temporal distribution of precipitation is of key importance for planning a wide range of socio-economic activities such as agriculture, livestock grazing, energy generation, etc. The availability of accurate and consistent precipitation data is then paramount for a proper assessment of such activities. However, traditional rain gauge measurements are relatively scarce and poorly distributed over the surface of the globe, particularly over remote areas or in developing countries. In the last three decades, satellite-derived precipitation estimate products have been developed using multi-satellites and multi-sensors. Such products provide an effective way of 
estimating precipitation data in areas where measurements are scarce, such as deserts [1], forests [2] and oceans [3]. Accordingly, they have been widely used in research and applications worldwide [4-7].

The first approaches to employ remote sensing techniques for estimating precipitation were performed during the 70s. During that time, satellite images were not digitized. Barret [8] was one of the pioneers in developing a method for estimating monthly precipitation, using the visible channel. This method was called "cloud index", and was later improved by Follansbee [9], which included estimations of daily precipitation rates. Almost two decades later, at the end of 1997, the Tropical Rainfall Measuring Mission (TRMM) [10] was launched jointly by NASA (National Aeronautics and Space Administration) and JAXA (Japan Aerospace Exploration Agency), aiming to improve precipitation estimates in tropical and subtropical regions. One of the most successful products generated from this mission is the Multi-Satellite Precipitation Analysis research version (TMPA) and the real-time version of the same product (TMPA-RT). Besides combining precipitation estimates derived from several satellites, the TMPA algorithm $[4,11,12]$ is also able to incorporate observed precipitation data [13]. Over the last decade, those retrievals have been greatly improved with different versions of those products. For this study, the version of TMPA launched in 2012 (version 7 or TMPA-V7 hereafter) will be used.

The TMPA product has been used in scientific research and operational activities which lead to outstanding socio-economic gains, such as studies of extreme precipitation events [14-16], forecasting of natural disasters [17,18], water resources management planning [19], performance of numerical models $[20,21]$, among others. Due to this, TMPA validation studies have been performed in several regions around the globe, and those results show great agreement between TMPA products and surface data $[17,22-26]$. Nevertheless, particularly over Brazilian territory, systematic bias are still observed for some precipitation regimes associated with shallow convection systems near the coast of northeastern Brazil (underestimation of precipitation) [27,28]. Conversely, in Southern Brazil (close to the border with Argentina and Paraguay), this algorithm overestimates the observed rainfall $[20,26]$. According to Laing and Fritsch [29], one of the largest and most active mesoscale convective complexes (MCCs) in the world is observed in this region.

In the beginning of 2014, the Global Precipitation Measurement (GPM) mission was launched to improve global estimates of precipitation and snow in low and mid latitudes. Moreover, GPM is a natural replacement of the successful TRMM mission [30]. The precipitation estimate algorithm created to replace TMPA is the IMERG (Integrated Multi-satellite Retrievals for GPM), made publicly available in the beginning of 2015 in the NASA portal [12]. This suite of products, namely IMERG-Early, IMERG-Late and IMERG-Final, is considered the next-generation of satellite-derived precipitation products, since it brings together resources from the existing: (1) TMPA [4], (2) CMORPH (Climate Prediction Center Morphing) [5], and (3) Precipitation Estimation from Remotely Sensed Information using Artificial Neural Networks-Cloud Classification System (PERSIANN-CCS) [6,31]. Because they are a recent effort, the products generated from GPM require urgent evaluation in order to be available for use, compared to other precipitation estimate products.

On the other hand, the Global Satellite Mapping of Precipitation (GSMaP) product, developed by a consortium of Japanese institutions and operated by JAXA [7,32], also offers a global coverage of rainfall with several versions: the real time version (GSMaP_NRT), the standard version (GSMaP_MVK) and the standard version with gauge correction (GSMaP-Gauge) [33]. The basic idea of the GSMaP algorithm is to find the optimal precipitation for which the brightness temperatures (TBs) calculated by the radiative-transfer model (RTM) fit best with observed TBs [7].

In view of the need to evaluate the accuracy of the new suite of GPM products in different regions of the globe, this study aims to assess the IMERG-Final and GSMaP-Gauge retrievals, in order to replace the TMPA research version in several regions with different precipitation regimes in Brazil. This paper is organized as follows: Section 2 provides details of the study area, the criteria used for the division of sub-areas according to precipitation regimes, and the datasets and statistics used; Sections 3 
and 4 present the main results of this research and a discussion. The main conclusions are provided in Section 5 .

\section{Materials and Methods}

\subsection{Area of Interest and Characterization of the Precipitation Regimes}

Brazil, due to its continental dimensions $\left(8,515,759 \mathrm{~km}^{2}\right.$ of territorial area), features a great diversity of landscapes, topography, biodiversity and climates, as well as of precipitation regimes. In order to evaluate the effectiveness of satellite-derived precipitation products in the country, it is necessary to contextualize the main precipitation regimes in Brazil. In order to do that, 18 years of precipitation data (1998-2016) from the MERGE product [34] were used. This product combines daily precipitation from rain gauge stations (see observed data section) with the TMPA_RT product. According to this study, the MERGE product has proven to be a valuable analysis tool for model evaluation, outperforming gauge analysis for those regions with low rain gauges density.

Figure 1 shows the spatial distribution of the precipitation climatology over Brazil based on MERGE data. This climatology was calculated for the whole country and divided into grid cells with $2 \times 2$ degrees. This spatial distribution fits very well with the study of Reboita et al. [35] based on gauge analysis. Considering these results and the Figure 3 of Reboita et al., five different precipitation regimes were identified within Brazilian territory. Region R1, located in southern Brazil, presents year-round well distributed precipitation, and high total precipitation: 1050-1750 mm/year. The main systems influencing this region are cold fronts, mesoscale convective complexes [36], the South Atlantic Convergence Zone (ZCAS) [37] and the low-level jet stream [38]. Region R2, with a clear monsoon regime [39], covers most of the Brazilian territory, where the accumulated precipitation is higher during summer (DJF) and lower during winter time (JJA). Region R3, the driest region of the Brazilian territory, is located inland over northeastern Brazil and also presents a maximum of precipitation during summer and a minimum during winter, with totals between 200 and $500 \mathrm{~mm} /$ year. The main systems influencing this region are the Intertropical Convergence zone (ITCZ) and upper level cyclonic vortexes [40]. Region R4 (located in the northeastern coast of Brazil) presents maximum precipitation in winter and minimum in summer. The main systems are the ITCZ, tropical mesoscale convective systems, the Trade Winds, upper level cyclonic vortexes, easterly waves and sea breeze circulation [41]. Region R5 comprises the northern Amazonian region; the main influencing systems are the ITCZ, the tropical squall lines [42] and the trade winds.

\subsection{Observed Data}

The 24-h accumulation of rain gauge data used in this study are received daily, in near real time, by the Centre for Weather Forecasting and Climatic Studies of Brazil (CPTEC/INPE), and cover the period 12 UTC to 12 UTC. Main sources of precipitation data are composed of the global telecommunication system (GTS), the automatic platform for collecting data (PCDs), and the regional meteorological centers in Brazil. Most surface stations are located in eastern Brazil, near the coast. Towards the center of the continent, the network density decreases sharply. A quality control of gauge data is performed in two stages: the first is objective and the second is subjective. The data is verified in real time, that is, at the time of storage in database systems. At this stage, validity, consistency (internal and spatial) and control (temporal and climatological) checks are performed. In the validity check, acceptable values must belong to a predefined interval (or be within a tolerance limit). Internal consistency performs validations of variables focused on internal relationships, considering a single weather station. The limits of the variables (precipitation, in this case) are reevaluated in a spatial consistency process, considering different climatic regions. This process also compares variables from different meteorological stations (for example, the precipitation of a station is compared with the precipitation of other stations within a distance of up to $25 \mathrm{~km}$ ). The temporal control verifies the differences of the variables over a given period (for example, precipitation is acceptable if the 
difference of its current value in relation to the previous value does not exceed $175 \mathrm{~mm}$ ). At the end of the first stage, the data are classified according to quality, by means of a descriptor, whose values are: suspect or correct. In the subjective stage, verification is performed by a meteorologist, who evaluates variables which have been identified as suspicious in the first stage. After the subjective analysis, suspect variables can be classified as valid or invalid. This process was carried out over 35 months, from the 1st of April, 2014, to the 28th of February, 2017; on average, 3400 daily observations were used in this study.

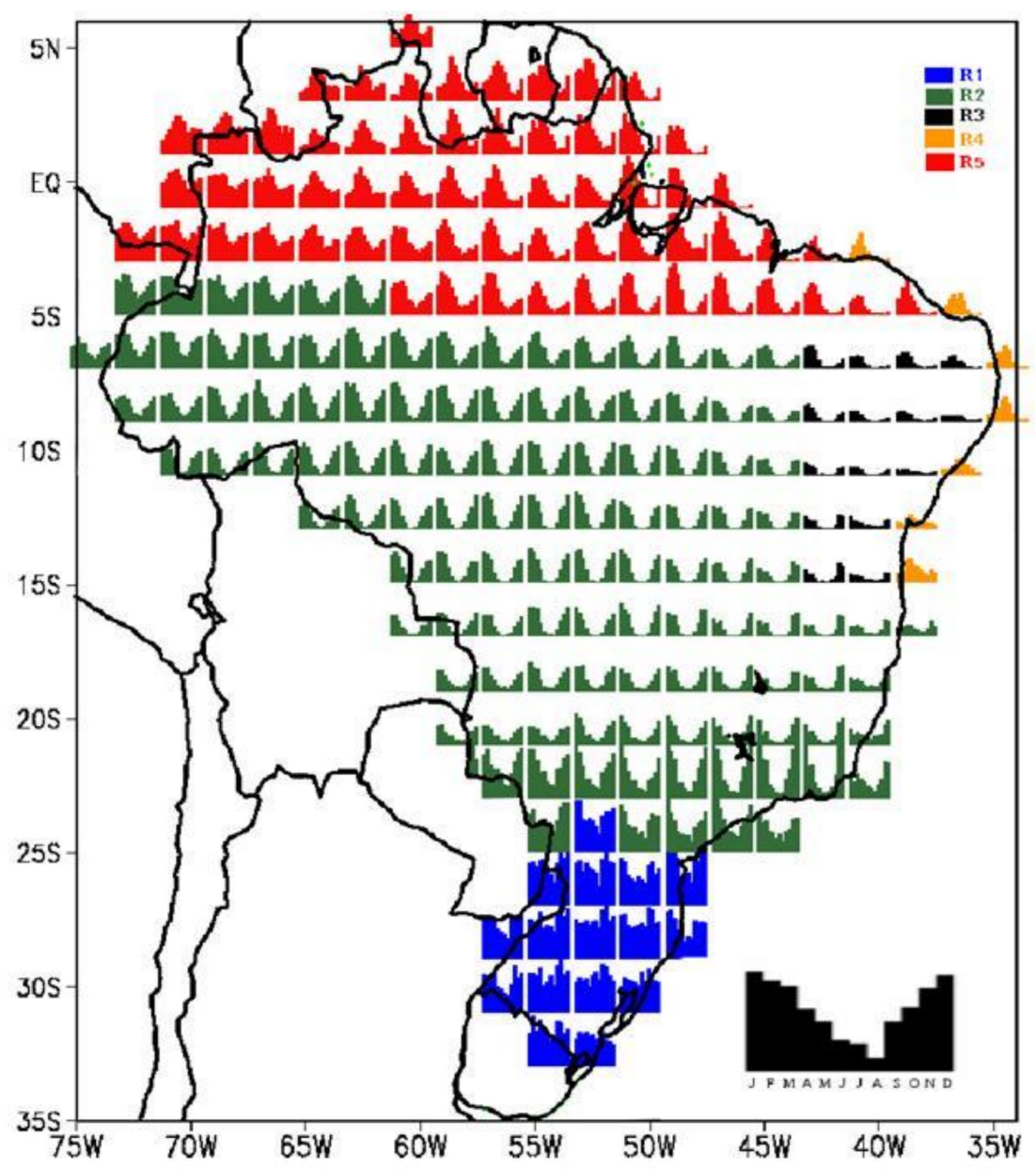

Figure 1. Spatial distribution of precipitation climatology (1998-2016) based on MERGE data [34] for the five identified regions, for each grid box of approximately 2 degrees.

\subsection{TMPA Products}

TMPA is responsible for two products: the research V7 version (TMPA), and the real-time version (TMPA-RT). Both are used extensively by a large community of users [11]. The products combine the estimates of precipitation from several satellite sensors. The biggest difference between them is that TMPA (TMPA-V7 hereafter) incorporates rainfall monthly data from the global rain gauge network (GPCC, Global Precipitation Climate Center) to scale the final product. These products are developed with a temporal resolution of $3 \mathrm{~h}$, and a horizontal resolution of $0.25^{\circ}$, covering most of the globe (between latitudes $50^{\circ} \mathrm{N}-\mathrm{S}$ ). TMPA products were accumulated over $24 \mathrm{~h}$, according to guidelines from the World Meteorological Organization. This is done in order to standardize the time of synoptic observations around the world, according to universal time: the total precipitation from 12 UTC of a given day up to 12 UTC of the following day is used. TMPA data were obtained via ftp from the US 
National Aeronautics and Space Administration (NASA) (https:// disc2.gesdisc.eosdis.nasa.gov/data). In order to use the final version of each product, TMPA-V7 will be used in this comparison.

\subsection{IMERG Product}

The Global Precipitation Measurement Core Observatory Satellite (GPM), launched on the 27th of February, 2014, aims to provide the next generation of precipitation products, continuing with the first-rate products provided by TMPA. Its algorithm, The Integrated Multisatellite Retrievals for GPM (IMERG), is similar to the algorithm of the TMPA products. It was built to calibrate, combine and interpolate satellite-derived precipitations (microwave, infrared) and worldwide observed data. IMERG is executed in near real-time for operational purposes and with two months' delay for the research version. It provides two near real-time precipitation estimates data options: Early and Late. Early provides a quick estimate, with a $4 \mathrm{~h}$ lag, taking into account only data which has been collected at that moment. Late has a 12-h lag (after more data has arrived), and is therefore obviously more precise. For the IMERG research product, estimates are combined with monthly observed data (similar procedure applied for TMPA-V7), and made available two months later (called IMERG-Final, hereafter IMERG-F).

IMERG-F product (version V05) used in this study were obtained from ftp://arthurhou.pps. eosdis.nasa.gov/gpmallversions/V05/with a temporal resolution of $30 \mathrm{~min}$ and $0.1^{\circ} \times 0.1^{\circ}$ of horizontal resolution. IMERG-F covers most of the globe: all surface area between latitudes $60^{\circ} \mathrm{N}$ and $60^{\circ} \mathrm{S}$, corresponding to $87 \%$ of the Earth's surface. According to WMO guidelines, IMERG-F data have also been accumulated over $24 \mathrm{~h}$, as well as TMPA-V7 data. The high spatial and temporal resolution, together with the expressive area of operation, make IMERG-F a potentially valuable tool for the scientific community. In this study, IMERG-F data (the research version) have been used for comparisons with other algorithms. More details on the GPM products and the IMERG algorithm can be found in [12].

\subsection{GSMaP Product}

Development of the precipitation map algorithm, including microwave radiometer/sounder algorithms, has been continued in cooperation with the members of Global Satellite Mapping of Precipitation (GSMaP) project [32] in Japan. Since the GSMaP project targeted the production of the "best" precipitation estimates, and they did not consider real-time operation and/or data availability, JAXA has developed and has operated a global rainfall map production system in near-real-time since October 2008; hourly and 0.1-degree resolution binary data and images are available via the internet (http:/ / sharaku.eorc.jaxa.jp/GSMaP/) four hours after observation. Core algorithms of the system are based on those provided by the GSMaP project; microwave radiometer rainfall retrieval algorithm [7], microwave sounder rainfall retrieval algorithm [43], microwave imager/sounder rainfall retrieval algorithm [44], microwave-infrared (IR) merged algorithm [45] and Gauge calibrated rainfall algorithm [33].

GSMaP-Gauge (hereafter GSMaP-G) is a product that adjusts the microwave-infrared (IR) merged algorithm (hereafter GSMaP_MVK) with the global gauge analysis (CPC Unified Gauge-Based Analysis of Global Daily Precipitation) supplied by NOAA. The product also has a spatial and temporal resolution of 0.1 degree and $1 \mathrm{~h}$. The 24-h accumulation product (12 UTC to 12 UTC) and version 7 , released in 2017, is used for this study.

\subsection{Statistical and Categorical Indexes}

Statistical and categorical indexes [46] are used to evaluate the TMPA-V7 (version 7), IMERG-F (version 5) and GSMaP-G (version 7) products. Tables 1-3 give short descriptions of those statistic parameters, while an intensity rain classification based on daily thresholds is presented in Table 4 . 
Table 1. Statistical indexes.

\begin{tabular}{ccc}
\hline Statistical Index & Equation & Optimal Value \\
\hline Root Mean Square Error & $R M S E=\sqrt{\frac{\sum_{i=1}^{N}\left(E_{i}-O_{i}\right)^{2}}{N}}$ & 0 \\
Mean Error & $M E=\frac{1}{N} \sum_{i=1}^{N}\left(E_{i}-O_{i}\right)$ & 0 \\
\hline
\end{tabular}

Table 2. Contingency Table.

\begin{tabular}{cccc}
\hline & Gauge Rain & Gauge No-Rain & Total \\
\hline Satellite rain & $\mathrm{a}=$ Hit & $\mathrm{b}=$ false alarm & $\mathrm{E}=(\mathrm{a}+\mathrm{b})$ \\
Satellite no-rain & $\mathrm{c}=$ miss & $\mathrm{d}=$ correct negative & $(\mathrm{c}+\mathrm{d})$ \\
Total & $\mathrm{O}=(\mathrm{a}+\mathrm{c})$ & $(\mathrm{b}+\mathrm{d})$ & $(\mathrm{a}+\mathrm{b}+\mathrm{c}+\mathrm{d})$ \\
\hline
\end{tabular}

Table 3. Categorical indexes.

\begin{tabular}{ccc}
\hline Categorical Index & Equation & Optimal Value \\
\hline & $E T S=\frac{\left(H_{a}-\frac{O * O}{N}\right)}{\left(E+O+H_{a}-\frac{O * O}{N}\right)}$ & \\
Adjusted Equitable Threat Score & Where, & 1 \\
(Mesinger, 2008) & $H_{a}=O *\left[1-\left(\frac{O-H}{O}\right)^{\frac{O}{E}}\right]$ & \\
Probability of detection & $P O D=\frac{H}{O}$ & 1 \\
False alarm ratio & $F A R=\frac{E-H}{E}$ & 0 \\
BIAS & $B I A S=\frac{E}{O}$ & 1 \\
Critical success index & $C S I=\frac{H}{E+O-H}$ & 1 \\
\hline
\end{tabular}

Table 4. Rain classification and thresholds.

\begin{tabular}{cc}
\hline Rain Intensity Classification & Precipitation Thresholds (mm) \\
\hline Rain/no-rain & 0.5 \\
Light & $2-5$ \\
Moderate & $10-20$ \\
Heavy & $35-50$ \\
\hline
\end{tabular}

\subsection{Standardization of Data}

Data used in this validation study are generated in different formats and spatial resolutions. GSMaP-G, IMERG-F and TMPA-V7 products are regularly spaced, although with degree resolutions of 0.10 for the first two and 0.25 for the third. Observations (OBS) are measured in fixed points (latitude, longitude and precipitation value), not following a regular spatial pattern, which requires a standardization of the dataset. In this study, we chose to evaluate the products of precipitation estimates in a coarser resolution grid ( 0.25 degrees). Standardization was performed following these steps:

(a) Using the position (latitude and longitude) of each station, satellite-based precipitation retrievals are extracted from TMPA-V7, IMERG-F and GSMaP-G products using the nearest neighbor approach (the closest center of the correspondent grid point is selected). This approach is the same as that used in [11] to retain the original retrieved value of each algorithm. In this case, the maximum distance between the center of the grid point and the gauge is approximately seven kilometers for IMERG-F and GSMaP-G, and eighteen kilometers for TMPA-V7 (below the nominal spatial resolution of the respective products);

(b) A table is built with the latitude and longitude of the station, observed precipitation and estimated precipitation for the three products following the procedure described in the paragraph above; 
(c) From this table, and using the same regularly spaced grid as that of the TMPA-V7 $\left(0.25^{\circ} \times 0.25^{\circ}\right)$, three grids with the averages of existing precipitations inside each grid point are calculated for IMERG-F, GSMaP-G and OBS. In the case of the TMPA-V7, the original value is preserved. These values represent the average precipitation at each grid point. Grid points with no existing gauges are flagged as invalid. Additionally, the average of the brightness temperature of GOES-13 channel 4 (10.8 microns) is also performed for those grid points with at least one gauge station. This variable, which represents the temperature of the top of the cloud, is used as a proxy to identify, in a very general way, the mean depth of the clouds;

(d) In order to perform a statistically robust study, only grid points with $50 \%$ or more of rain gauge data frequency, using the entire time series, were considered. The spatial distribution of points which satisfy this criterion is shown in Figure 2. Table 5 shows the amount of valid grid points per region.

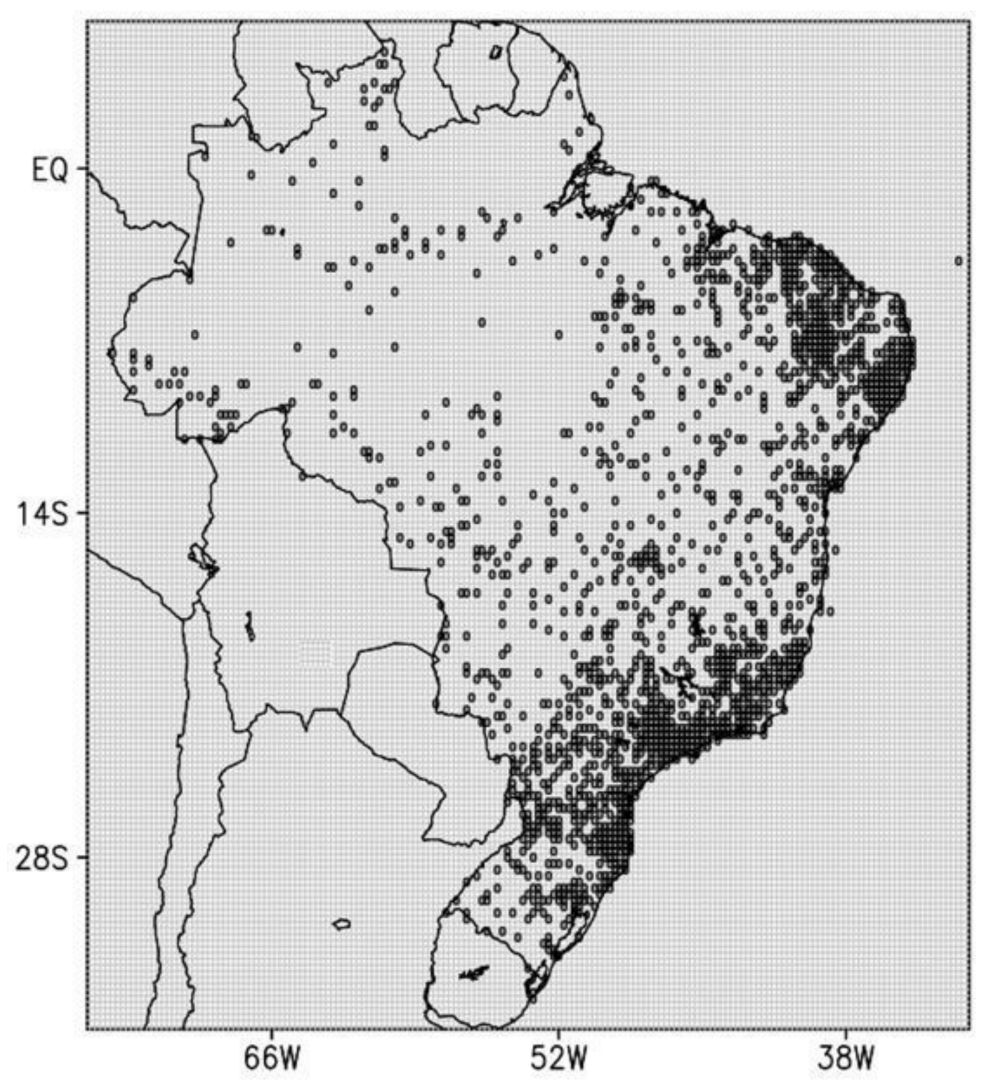

Figure 2. Spatial distribution of grid points which present rain gauge data frequency of at least $50 \%$ in the studied period, and in regularly spaced grids of $0.25^{\circ}$.

Table 5. Number of valid grid points for each region.

\begin{tabular}{cc}
\hline Region & N. of Grid Points \\
\hline R1 & 271 \\
R2 & 892 \\
R3 & 270 \\
R4 & 222 \\
R5 & 124 \\
BRAZIL & 1779 \\
\hline
\end{tabular}




\section{Results}

\subsection{Temporal Evolution}

Figure 3 shows the temporal evolution of the daily averages of TMPA-V7, IMERG-F, GSMaP-G observed precipitation (gauges), and brightness temperature from GOES-13 (Geostationary Operational Environmental Satellite) for Brazil and its five precipitation sub-regions. Brightness temperature is used here as a proxy in order to identify cloud top types (cold or warm) in each region. In order to smooth the higher frequencies of the time-series of each variable, a 10-day moving average was applied to all aforementioned variables.
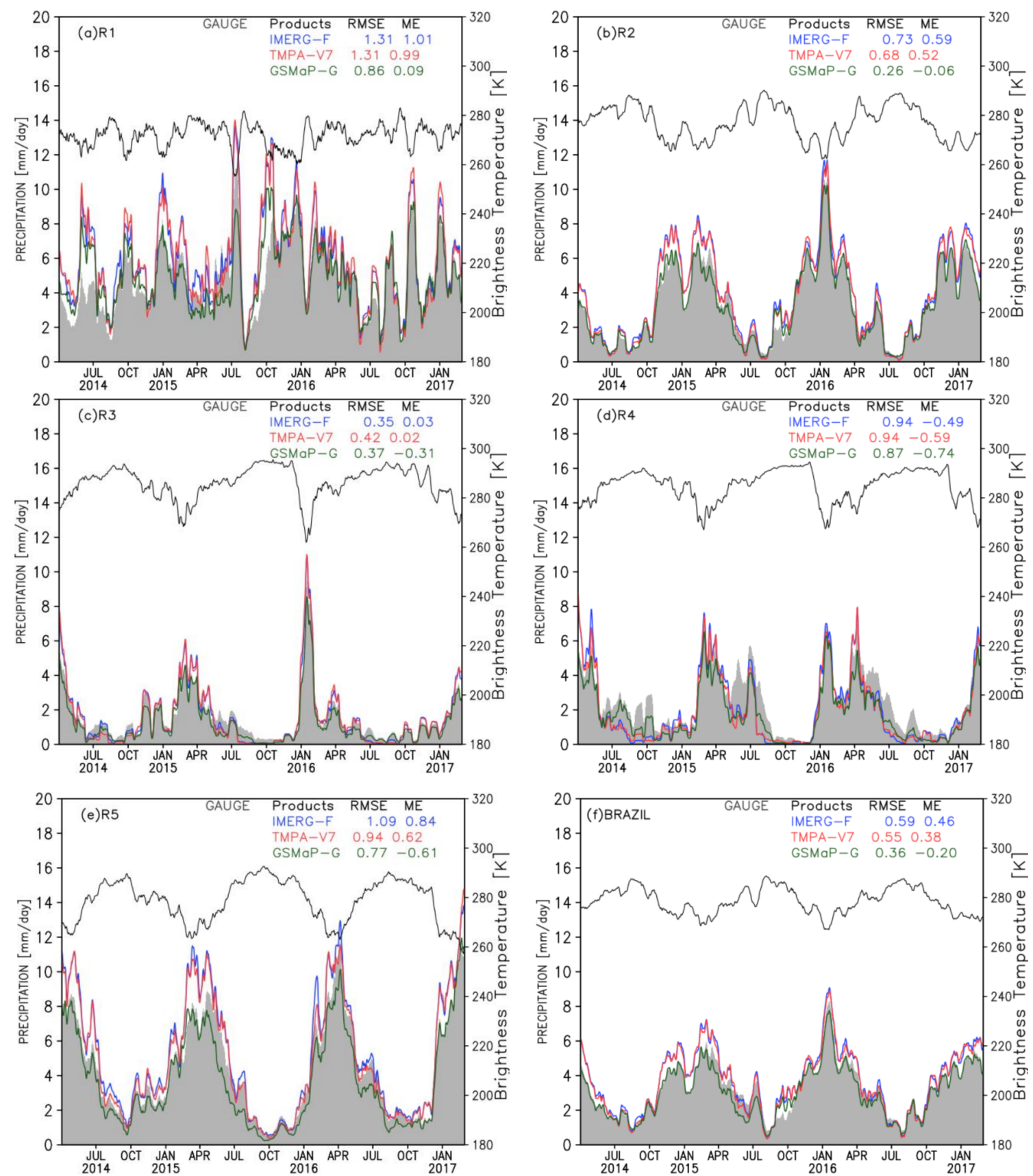

Figure 3. Temporal evolution of daily averages of the precipitation estimate products IMERG-F (blue), TMPA-V7 (red) and brightness temperature (black) from GOES-13 (Geostationary Operational Environmental Satellite) for the R1 (a), R2 (b), R3 (c), R4 (d), R5 (e) regions, and whole Brazil (f). 
In $\mathrm{R} 1$ region (Figure 3a), considering the 271 valid grid points, TMPA-V7 and IMERG-F show similar behavior: both algorithms overestimate the accumulated daily precipitation. The overestimation is more evident from 2014 to the end of 2016, compared to that of the rest of the period. During this period, brightness temperature is highly correlated (negatively) with observed and estimated precipitation. The periods with larger overestimation of precipitation correspond to the lowest brightness temperature values. This behavior suggests the presence of deep convection systems (with large amount of ice on its structure), where larger amount of rainfall is estimated than is actually occurring. In this case, both products have the same RMSE value $(1.31 \mathrm{~mm} /$ day $)$, while the ME associated with TMPA-V7 (0.99 mm/day) is slightly lower than IMERG-F (1.01 mm/day). In the case of the GSMaP-G, the mean value is always below TMPA-V7 and IMERG-F retrievals, and close to observed values. This result suggests that the CPC Unified Gauge-Based Analysis of Global Daily precipitation used to adjust the bias in GSMaP-G (Ushio et al., 2013) is performing better than the monthly accumulation used to scale the NASA final products (TMPA-V7 and IMERG-F). For this region, ME is close to 0 and RMSE is $0.86 \mathrm{~mm}$ /day for GSMaP-G.

R2 region (Figure 3b), with 892 valid grid points, is the largest evaluated region. The behavior of maximum precipitation in summer and minimum in winter is estimated efficiently by all products. However, overestimation is also present along the studied period (mainly during summer time) for TMPA-V7 and IMERG-F, while GSMaP represents that peak better. As within R1 region, R2 region is influenced by deep convective systems, and the same behavior was seen: larger precipitation values were observed during periods with minimum brightness temperatures (generally summer months). In this region, RMSE $(0.68 \mathrm{~mm} /$ day $)$ and ME $(0.52 \mathrm{~mm}$ /day) values for TMPA-V7 were slightly lower than RMSE (0.73 mm/day) and ME (0.59 mm/day) values from IMERG-F, while GSMaP-G has the lower values for all algorithms: $0.26 \mathrm{~mm}$ /day for RMSE and $-0.06 \mathrm{~mm} /$ day for ME.

R3 region (Figure 3c), with 270 valid grid points, presents the lowest precipitation totals among all regions. All products showed similar behavior and are able to effectively estimate the precipitation regime in most of the analyzed period, except for a general tendency for overestimation during the wet season by TMPA-V7 and IMERG-F, and underestimation by GSMaP-G. However, in terms of ME, IMERG-F and TMPA-V7 have the lowest values, with 0.03 and $0.02 \mathrm{~mm} /$ day respectively. GSMaP-G has a negative bias of $-0.31 \mathrm{~mm} /$ day, due to underestimation during the transition from the wet to the dry season (approximately April-August each year). RMSE values show that IMERG-F is slightly better that GSMaP-G (0.35 an $0.37 \mathrm{~mm}$ /day respectively) while TMPA-V7 has the worst performance (0.42 mm/day).

R4 (with 222 valid grid points) present the least accurate estimate of the precipitation regime of all products (Figure 3d). As observed in other regions, the behavior of all products is similar. During most of the period, there is an underestimation in precipitation values from all products, especially in days when brightness temperatures are higher (above $285 \mathrm{~K}$ ). In this situation, precipitation is associated with systems with warm cloud tops. However, for precipitation systems characterized by cold cloud tops (relative minimum values of brightness temperature), better results are obtained. In this region, TMPA-V7 and IMERG-F show the same RMSE value $(0.94 \mathrm{~mm} /$ day $)$, but the ME is slightly lower for IMERG-F ( $-0.49 \mathrm{~mm} /$ day). For GSMaP-G, RMSE is $0.87 \mathrm{~mm} /$ day, the best value among all algorithms, whereas $\mathrm{ME}$ is $-0.74 \mathrm{~mm} /$ day, the largest (negative) bias for all products.

R5 region (Figure 3e), located in the extreme north of the country, presents the lowest coverage of observed data (124 valid grid points). The annual precipitation cycle, with maximum values in March/April and minimum values in October, is relatively well represented, although with some overestimation for TMPA-V7 and IMERG-F and underestimation for GSMaP-G. In this particular region GSMaP-G has the best performance in terms of RMSE: 30\% and 18\% better than IMERG-F and TMPA-V7 respectively. In this region, RMSE $(0.94 \mathrm{~mm} /$ day $)$ and ME $(0.62 \mathrm{~mm} /$ day $)$ values for TMPA-V7 were slightly lower than RMSE (1.09 mm/day) and ME (0.84 mm/day) values from IMERG-F, while GSMaP-G has lower values for all algorithms: $0.77 \mathrm{~mm} /$ day for RMSE and $-0.61 \mathrm{~mm} / \mathrm{day}$ for 
ME. A negative correlation between brightness temperature and the precipitation estimate is quite evident in this region.

Considering the whole Brazilian territory (Figure 3f), results are quite similar to those found in region R2, with maximum precipitation totals in January and minimum totals in July. This occurs due to the largest extent of region R2 in area and valid grid point of observations (about $59 \%$ of the total).

\subsection{Quantitative Precipitation Forecast (QPF)}

In this section, quantitative results will be presented for eight precipitation thresholds- $0.5,2,5$, $10,15,20,35$ and $50 \mathrm{~mm}$, based on a contingency table (Table 3). As with the previous section, only grid points with at least $50 \%$ of observed data are considered in this analysis.

Figure 4 shows the Equitable Threat Score (ETS) for both evaluated products. ETS analysis for region R1 (Figure 4a) shows that GSMaP-G presented the best performance for all precipitation thresholds. The lowest ETS values, as expected, are observed during intense precipitation episodes (more than 50mm). In general, the ETS for GSMaP-G is about 20\% higher than IMERG-F, and 35\% better than TMPA-V7. Considering that ETS measures the fraction of observed grid points for a given threshold that were correctly estimated by a given algorithm, adjusted for hits associated with random chance, this score is showing that daily gauge adjustment used by GSMaP-G is adding some extra value compared with monthly-adjusted algorithms (TMPA-V7 and IMERG-F). Because ETS allows scores to be compared more fairly across different regimes, it is possible to conclude that R1 presents the best performance for all products.

$\mathrm{R} 2$ region (Figure $4 \mathrm{~b}$ ) presents ETS values slightly lower than in R1, showing that precipitation estimates in region R1 are more accurate. The GSMaP-G product exhibits better performance for all precipitation thresholds. Above $2 \mathrm{~mm}$ threshold, all products show a considerable decrease in performance. In most of the thresholds, the performance of GSMaP-G is about $30 \%$ better than IMERG-F, while TMPA-V7 is always on the low end for all thresholds.

Inner northeastern Brazil, represented by region R3 (Figure 4c), shows different behavior compared to that of regions R1 and R2. While GSMaP-G has an almost constant value up to $5 \mathrm{~mm}$, an increase in ETS values from the 0.5 to the $5.0 \mathrm{~mm}$ threshold is observed for TMPA-V7 and IMERG-F. However, there is a decrease in performance, as expected. In all thresholds, GSMaP-G is superior to IMERG-F and TMPA-V7. This is more evident for lower rain rates (below $5 \mathrm{~mm} /$ day). The performance of all products in this region is considerably lower than that in regions R1 and R2.
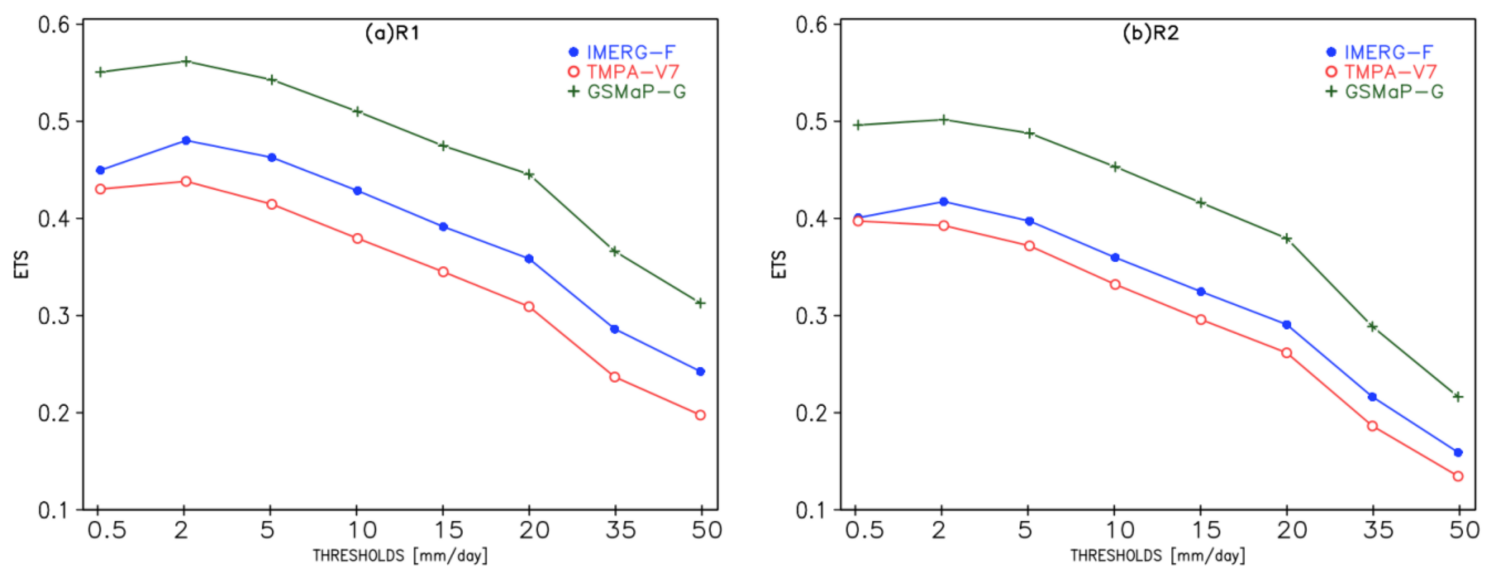

Figure 4. Cont. 

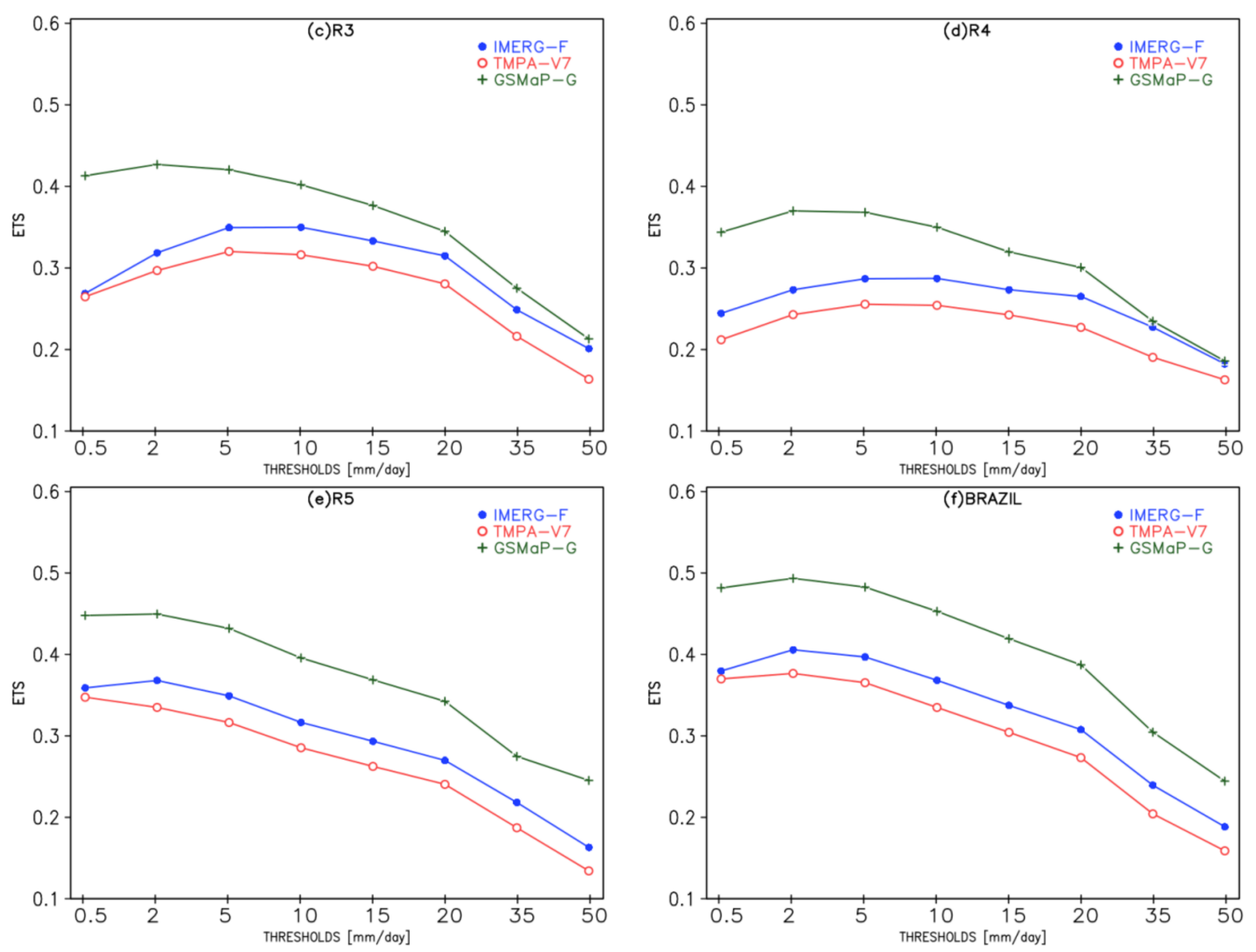

Figure 4. Equitable Threat Score (ETS), considering the whole studied period, for regions R1 (a), R2 (b), R3 (c), R4 (d), R5 (e) and Brazil (f).

The Eastern coast of northeastern Brazil, corresponding to region R4 (Figure 4d), shows the worst performance for all products among all regions. The performance of GSMaP-G is higher in this region for all thresholds, with a similar pattern to region R3. This might be attributed to the presence of warm clouds system. Palhiarini and Vila (2017) concluded, using 17 years of TRMM-PR (TRMM-precipitation radar) data, that shallow convection is the predominant cloud type system during the rainy season in this region. The lack of ice in precipitating clouds is this region makes it very difficult for microwave sensors to retrieve rainfall using high frequency channels (Braga, 2014).

In region R5 (Figure 4e), the ETS values for GSMaP-G are higher than those of NASA products. When considering the whole country (Figure 4f), the ETS values, as expected, are higher for GSMaP-G for all precipitation thresholds.

Figure 5 presents the performance diagram [47] of IMERG-F (blue), GSMaP-G (green) and TMPA-V7 (red) products. The circles represent the precipitation thresholds. The smallest circle represents the rain-no rain threshold, and the largest circle, the threshold above $50 \mathrm{~mm}$. This diagram makes it easier to analyze the results, as it represents several dichotomic (yes/no) quality measures simultaneously, such as the POD, BIAS, CSI and FAR. Dashed lines represent BIAS, and solid lines the CSI. Thus, the best estimates are located in the upper right part of the diagram. 

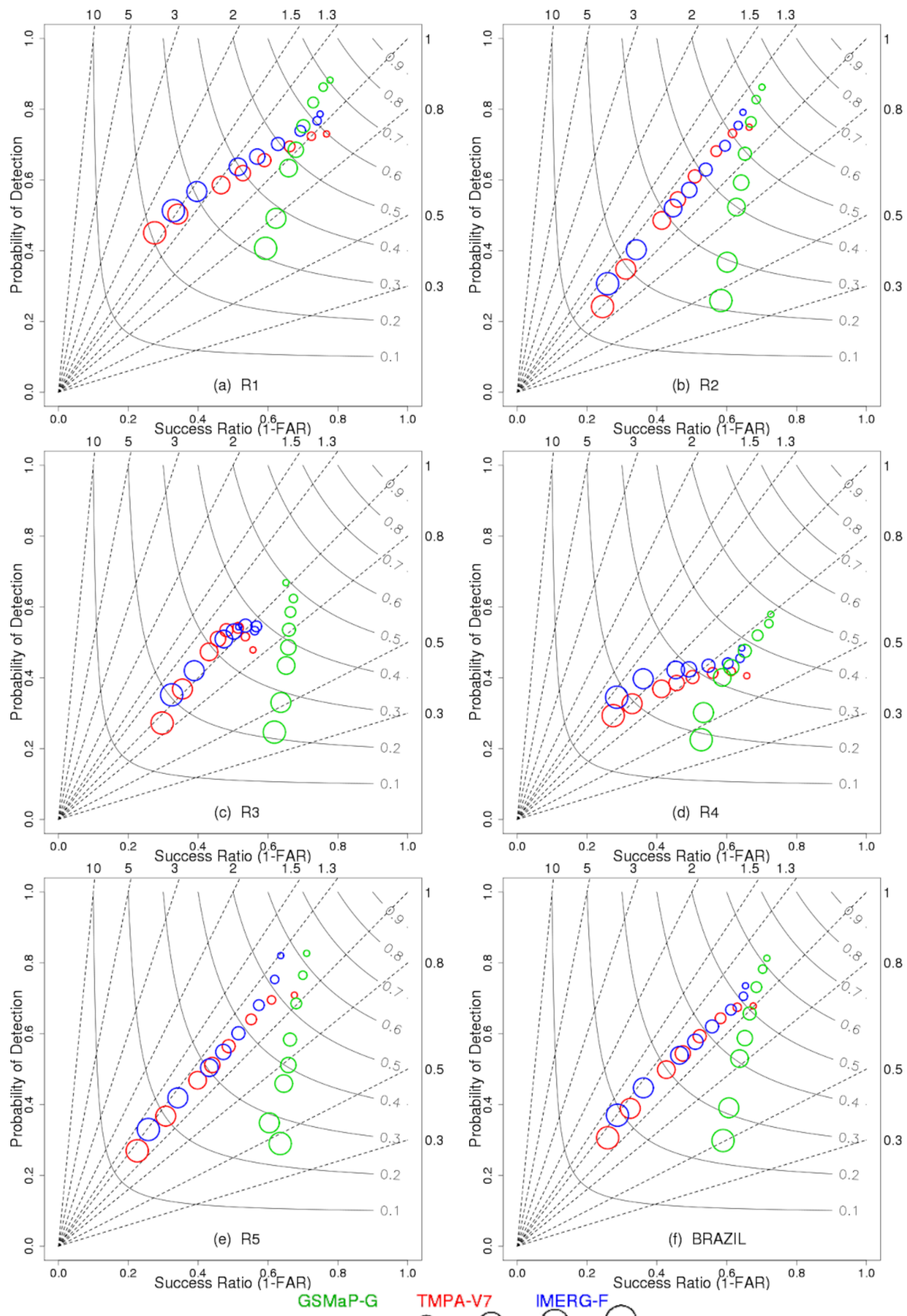

$00.5 \quad O_{2} \quad O_{5} \bigcirc_{10} \bigcirc_{15} \bigcirc_{20} \bigcirc_{35} \bigcirc_{50}(\mathrm{~mm})$

Figure 5. Performance diagram [47] summarizing the SR, POD, BIAS, and CSI for regions R1 (a), R2 (b), R3 (c), R4 (d), R5 (e) and BRAZIL (f). Dashed lines represent BIAS scores with labels on the outward extension of the line, while labelled solid contours are CSI. Circles represent the eight precipitation thresholds. The smallest circle represents the rain/no rain threshold $(0.5 \mathrm{~mm})$, and the largest circle represents the threshold above $50 \mathrm{~mm}$. 
The CSI for R1 region (Figure 5a) indicates better performance for the GSMaP-G product, followed by the GMP_F, and finally by TMPA-V7 for all thresholds analyzed. CSI for GSMaP-G is around 13\% higher than the IMERG-F, and 20\% higher than the TMPA-V7. In terms of FAR, it is observed that for thresholds below $2.0 \mathrm{~mm}$, the results are similar among all three products, but for higher thresholds, FAR values for GSMaP-G are significantly lower. When this result is combined with a BIAS score below 0.8 , indicates that GSMaP-G is missing high precipitation events in this region, while the relatively higher FAR value for NASA products, combined with BIAS around 1.5 is related with overestimation of the area with heavy precipitation rates (20-50 $\mathrm{mm} /$ day).

A similar analysis could be done for R2 (Figure 5b): GSMaP-G has better performance in terms of CSI, followed by IMERG-F and TMPA-V7. However, GSMaP-G is missing moderate and heavy rain events (low FAR and BIAS < 1), while IMERG-F and TMPA-V7 slightly overestimate the area for moderate and light rain rates.

For R3 region (Figure 5c), as was observed for R1 and R2, GSMaP-G exhibits higher CSI values for all thresholds when compared to the other two products. However, the underestimation of the area with rainfall (BIAS $<1$ ) is present in GSMaP-G for all thresholds. The BIAS for IMERG-F and TMPA-V7 are close to 1, which means that the area with precipitation above a given threshold is correctly estimated. Low POD and high FAR values for high rain rates suggest that those high impact events are not correctly placed for NASA products.

Among all the analyzed regions, the R4 region (Figure $5 \mathrm{~d}$ ) shows the lowest performance. The same behavior observed in other regions is observed here. The main difference is the underestimation of the area for IMERG-F and TMPA-V7 for moderate and light rain rates.

R5 region (Figure 5e) has a similar patter than R2, the largest analyzed region. GSMaP-G has better performance in term of CSI, followed by IMERG-F and TMPA-V7. However, GSMaP-G is missing moderate and heavy rain events (low FAR and BIAS < 1), while IMERG-F and TMPA-V7 slightly overestimate the area for all rainfall threshold.

It is not surprising that Brazil, as a whole region (Figure 5d), shows a similar pattern to that of the $\mathrm{R} 2$ region. Because the largest number of gauges are found in $\mathrm{R} 2$, the weight in the final result is larger than other regions. However, the behavior of the analyzed categorical indexes is quite similar along all different rainfall regimes.

\section{Discussion}

The performance of precipitation estimate products, obtained using three state-of-the-art algorithms for GPM era, namely IMERG-F and TMPA-V7 from NASA and GSMaP-G from JAXA, were evaluated in five Brazilian regions with different precipitation regimes, and the whole Brazilian territory, during the period from April 2014 to February 2017. From a broad perspective, and considering the amount of rainfall, GSMaP-G has the lowest ME and RMSE when compared with NASA products for most of the regions, except for R4. This is also true for categorical indexes like CSI and ETS. However, when the area of rainfall above a certain threshold is evaluated, GSMaP tends to miss moderate and heavy precipitation events in almost all areas. These results are in a good agreement with other studies like [48], where IMERG-F overestimates extreme precipitation indices, but GSMaP-G shows a significant underestimation in several basins in China.

In this section, the possible reasons for this behavior will be discussed, considering the characteristics of each database. In this study, gauge bias-adjusted versions were selected as the final products for each algorithm to make a fair comparison. However, while for IMERG-F and TMPA-V7 this procedure is done using monthly totals from GPCC [13], in the case of GSMaP, a daily gauge analysis (CPC Unified Gauge-Based Analysis of Global Daily Precipitation) supplied by CPC/NOAA is used.

In the first case, the hourly accumulated rainfall (or 3-hourly, in case of TRMM-V7) is obtained using the monthly GPCC precipitation gauge analysis (over land) in a three-step process. First, the gauge analysis is adjusted by multiplying the monthly precipitation values with the corresponding 
month's gridbox climatological adjustment ratios. Second, the multi-satellite estimate is adjusted to the large-scale mean of the gauges. Finally, the adjusted multi-satellite and gauge fields are combined using weighting by inverse estimated error variance [4]. In the case of GSMaP-G, the CPC Unified Gauge-Based Analysis of Global Daily Precipitation is applied based on the optimal theory which adjusts the GSMaP-Gauge hourly rain rate, so that the sum of the $24 \mathrm{~h} \mathrm{GSMaP-G}$ rain rate is roughly same as the gauge measurement where those gauges are available [33].

The observational database used as ground truth, as described in Section 2.2, is composed of the global telecommunication system (GTS), the automatic platform for collecting data (PCDs), and the gauge data from regional meteorology centers in Brazil. Because NOAA receives some of those gauges in real time, they are also included in the CPC Unified Gauge-Based Analysis of Global Daily Precipitation product. In such cases, the observational and the GSMaP-G database are not completely independent. During the period of this study, the mean number of gauges used for validation was around 3400 per day, while CPC Unified Gauge-Based Analysis of Global Daily Precipitation uses approximately 1000 gauges per day (on average). This could explain the lower ME and RMSE of this algorithm compared to those of NASA products for the regions with largest amount of gauges (R1 and R2). However, this fact does not exclude this product from the comparison, because, even considering this limitation, this algorithm shows some characteristics which are interesting to consider: (i) it represents state-of-theart of satellite rainfall retrievals at JAXA (a partner of GPM program) with continuous developments and reprocessing cycles; (ii) it does not reproduce for all times, all regions and all periods, the evolution of the observed precipitation, which means that some degree of independent data remains in the database (Figure 3), and (iii) this gauge-adjusted product is the only one which is available in near real-time (4 days), compared with the two months' latency for IMERG-F and TMPA-V7. This last issue is quite important for some applications, such as hydrological forecasting (dams management) for hydropower and irrigation, and other users where the latency plays a vital role in the decision making process and for which the accuracy of retrieval should be above certain threshold which cannot be reached using the satellite-only versions (real time versions).

In the case of NASA products, the mean number of gauges available in the GPCC database used for bias correction in the final products over Brazil for the period 2014-2017 is around 300. This number is less than $10 \%$ of gauge data available for validation ( 3400). Even those databases (TMPA-V7 and IMERG-F) are also not completely independent; a larger 'degree of independence' is achieved when compared with GSMaP-G.

Future validation studies should include no gauge-adjusted versions of these algorithms and fully independent observed data (i.e., radar estimates), to come to more conclusive results about the performance of these algorithms.

\section{Conclusions}

The performance of three satellite-based rainfall estimation products were evaluated in five Brazilian regions with different precipitation regimes, and the whole Brazilian territory, during the period from April 2014 to February 2017. Generally speaking, all products are able to estimate, with different degrees of accuracy, the levels of precipitation over the Brazilian territory. While overestimations are present in most of the studied regions for NASA products, GSMaP-G tend to slightly underestimate the observed rainfall. The most noticeable estimation errors for all products occur over the eastern coast of northeastern Brazil (region R4), where large underestimation for all products occurred during precipitation episodes caused by warm clouds. The quantitative analysis (ETS and CSI) shows that the GSMaP-G product presents better performance in all regions and all precipitation thresholds, while large underestimation of the area covered with heavy rainfall (rain rates $>100 \mathrm{~mm} /$ day) is also observed for this algorithm (Figure 5). IMERG-F and TMPA-V7 show similar behavior in terms of CSI, ETS, POD, FAR and BIAS with a better performance for IMERG-F.

This study shows that GSMaP-G and IMERG-F precipitation products exhibit better performance compared to the current TMPA-V7, besides the finer horizontal and temporal resolution of the new 
generation products. In this context, GSMaP-G and IMERG-F algorithms are a great replacements for TMPA-V7 products in the Brazilian territory, characterized by high density of river basins throughout its territory, where flood and landslide events are common, with negative social and environmental impacts. However, the choice of a given product will depend on the user's needs: GSMaP-G has a lower latency and tends to represent better to total amount of rainfall, while IMERG-F is more accurate for the retrieval of moderate and heavy rainfall events in terms of frequency (area).

Acknowledgments: The authors express their sincere thanks to the scientists in the National Aeronautics and Space Administration (NASA) and Japan Aerospace Exploration Agency (JAXA), responsible for the development of IMERG-F, TMPA-V7 and GSMaP-G algorithms and for providing satellite precipitation data. They also acknowledge the Center for Weather Forecast and Climate Studies for the gauge data database utilized in this study. The second author would like to acknowledge to Fundação de Amparo à Pesquisa do Estado de São Paulo (FAPESP) project 2015/14497-0 “Previsão Imediata de Tempestades Intensas e Entendimento dos Processos Físicos no Interior das Nuvens: O SOS-CHUVA (Sistema de Observação e Previsão de Tempo Severo)".

Author Contributions: José Roberto Rozante and Daniel A. Vila conceived the structure of this paper, and contributed to the discussion of scientific problems and the analysis of the results. Júlio Barboza Chiquetto, Alex de A. Fernandes and Débora Souza Alvim contributed to the data processing. All the authors conducted the manuscript revision.

Conflicts of Interest: The authors declare no conflict of interest.

\section{References}

1. Kelley, O.A. Where the Least Rainfall Occurs in the Sahara Desert, the TRMM Radar Reveals a Different Pattern of Rainfall Each Season. J. Clim. 2014, 27, 6919-6939. [CrossRef]

2. Knox, R.; Bisht, G.; Wang, J.; Bras, R. Precipitation Variability over the Forest-to-Nonforest Transition in Southwestern Amazonia. J. Clim. 2011, 24, 2368-2377. [CrossRef]

3. Short, D.A.; Nakamura, K. TRMM Radar Observations of Shallow Precipitation over the Tropical Oceans. J. Clim. 2000, 13, 4107-4124. [CrossRef]

4. Huffman, G.J.; Bolvin, D.T.; Nelkin, E.J.; Wolff, D.B.; Adler, R.F.; Gu, G.; Hong, Y.; Bowman, K.P.; Stocker, E.F. The TRMM Multisatellite Precipitation Analysis (TMPA): Quasi-Global, Multiyear, Combined-Sensor Precipitation Estimates at Fine Scales. J. Hydrometeorol. 2007, 8, 38-55. [CrossRef]

5. Joyce, R.J.; Janowiak, J.E.; Arkin, P.A.; Xie, P. CMORPH: A Method that Produces Global Precipitation Estimates from Passive Microwave and Infrared Data at High Spatial and Temporal Resolution. J. Hydrometeorol. 2004, 5, 487-503. [CrossRef]

6. Sorooshian, S.; Hsu, K.-L.; Gao, X.; Gupta, H.V.; Imam, B.; Braithwaite, D. Evaluation of PERSIANN System Satellite-Based Estimates of Tropical Rainfall. Bull. Am. Meteorol. Soc. 2000, 81, 2035-2046. [CrossRef]

7. Aonashi, K.; Awaka, J.; Hirose, M.; Kozu, T.; Kubota, T.; Liu, G.; Shige, S.; KIDA, S.; Seto, S.; Takahashi, N.; Takayabu, Y.N. GSMaP Passive Microwave Precipitation Retrieval Algorithm: Algorithm Description and Validation. J. Meteorol. Soc. Jpn. 2009, 87A, 119-136. [CrossRef]

8. Barrett, E.C. The estimation of monthly rainfall from satellite. Mon. Weather Rev. 1970, 98, 322-327. [CrossRef]

9. Follansbee, W.A. Estimation of Average Daily Rainfall from Satellite Cloud Photographs. 1973. Available online: https: / trove.nla.gov.au/work/17767436? selectedversion=NBD6944042 (accessed on 21 August 2017).

10. Kummerow, C.; Barnes, W.; Kozum, T.; Shiue, J.; Simpson, J. The Tropical Rainfall Measuring Mission (TRMM) Sensor Package. J. Atmos. Ocean. Technol. 1998, 15, 809-817. [CrossRef]

11. Huffman, G.J.; Adler, R.F.; Bolvin, D.T.; Nelkin, E.J. The TRMM Multi-Satellite Precipitation Analysis (TMPA). In Satellite Rainfall Applications for Surface Hydrology; Springer: Dordrecht, The Netherlands, 2010; pp. 3-22.

12. Huffman, G.J.; Bolvin, D.T.; Braithwaite, D.; Hsu, K.; Joyce, R.; Xie, P.; Yoo, S.-H. NASA global precipitation measurement (GPM) integrated multi-satellite retrievals for GPM (IMERG). Algorithm Theor. Basis Doc. Version $2015,4,30$.

13. Schneider, U.; Becker, A.; Finger, P.; Meyer-Christoffer, A.; Ziese, M.; Rudolf, B. GPCC's new land surface precipitation climatology based on quality-controlled in situ data and its role in quantifying the global water cycle. Theor. Appl. Climatol. 2014, 115, 15-40. [CrossRef]

14. Hamada, A.; Murayama, Y.; Takayabu, Y.N. Regional Characteristics of Extreme Rainfall Extracted from TRMM PR Measurements. J. Clim. 2014, 27, 8151-8169. [CrossRef] 
15. Agel, L.; Barlow, M.; Qian, J.-H.; Colby, F.; Douglas, E.; Eichler, T. Climatology of Daily Precipitation and Extreme Precipitation Events in the Northeast United States. J. Hydrometeorol. 2015, 16, 2537-2557. [CrossRef]

16. Huang, Y.; Chen, S.; Cao, Q.; Hong, Y.; Wu, B.; Huang, M.; Qiao, L.; Zhang, Z.; Li, Z.; Li, W.; et al. Evaluation of Version-7 TRMM Multi-Satellite Precipitation Analysis Product during the Beijing Extreme Heavy Rainfall Event of 21 July 2012. Water 2013, 6, 32-44. [CrossRef]

17. Li, L.; Hong, Y.; Wang, J.; Adler, R.F.; Policelli, F.S.; Habib, S.; Irwn, D.; Korme, T.; Okello, L. Evaluation of the real-time TRMM-based multi-satellite precipitation analysis for an operational flood prediction system in Nzoia Basin, Lake Victoria, Africa. Nat. Hazards 2009, 50, 109-123. [CrossRef]

18. Dinis, P.A.; Mantas, V.; Andrade, P.S.; Tonecas, J.; Kapula, E.; Pereira, A.; Carvalho, F.S. Contribution of TRMM rainfall data to the study of natural systems and risk assessment. Cases of application in SW Angola. Estudos Quaternário 2013, 9, 33-43.

19. Siddique-E-Akbor, A.H.M.; Hossain, F.; Sikder, S.; Shum, C.K.; Tseng, S.; Yi, Y.; Turk, F.J.; Limaye, A. Satellite Precipitation Data-Driven Hydrological Modeling for Water Resources Management in the Ganges, Brahmaputra, and Meghna Basins. Earth Interact. 2014, 18, 1-25. [CrossRef]

20. Rozante, J.R.; Cavalcanti, I.F.A. Regional Eta model experiments: SALLJEX and MCS development. J. Geophys. Res. 2008, 113, D17106. [CrossRef]

21. Da Rocha, R.P.; Morales, C.A.; Cuadra, S.V.; Ambrizzi, T. Precipitation diurnal cycle and summer climatology assessment over South America: An evaluation of Regional Climate Model version 3 simulations. J. Geophys. Res. 2009, 114, D10108. [CrossRef]

22. Nicholson, S.E.; Some, B.; McCollum, J.; Nelkin, E.; Klotter, D.; Berte, Y.; Diallo, B.M.; Gaye, I.; Kpabeba, G.; Ndiaye, O.; et al. Validation of TRMM and Other Rainfall Estimates with a High-Density Gauge Dataset for West Africa. Part II: Validation of TRMM Rainfall Products. J. Appl. Meteorol. 2003, 42, 1355-1368. [CrossRef]

23. Zou, C.-Z.; Zheng, W. Simulation of diurnal patterns of summer precipitation in the North American monsoon: An assessment using TRMM. Geophys. Res. Lett. 2004, 31. [CrossRef]

24. Wolff, D.B.; Marks, D.A.; Amitai, E.; Silberstein, D.S.; Fisher, B.L.; Tokay, A.; Wang, J.; Pippitt, J.L. Ground Validation for the Tropical Rainfall Measuring Mission (TRMM). J. Atmos. Ocean. Technol. 2005, 22, 365-380. [CrossRef]

25. Dinku, T.; Ceccato, P.; Grover-Kopec, E.; Lemma, M.; Connor, S.J.; Ropelewski, C.F. Validation of satellite rainfall products over East Africa's complex topography. Int. J. Remote Sens. 2007, 28, 1503-1526. [CrossRef]

26. Su, F.; Hong, Y.; Lettenmaier, D.P. Evaluation of TRMM Multisatellite Precipitation Analysis (TMPA) and Its Utility in Hydrologic Prediction in the La Plata Basin. J. Hydrometeorol. 2008, 9, 622-640. [CrossRef]

27. Franchito, S.H.; Rao, V.B.; Vasques, A.C.; Santo, C.M.E.; Conforte, J.C. Validation of TRMM precipitation radar monthly rainfall estimates over Brazil. J. Geophys. Res. 2009, 114, D02105. [CrossRef]

28. Palharini, A.; Santos, R.; Vila, D.A. Climatological Behavior of Precipitating Clouds in the Northeast Region of Brazil. Adv. Meteorol. 2017, 2017, 12. [CrossRef]

29. Laing, A.G.; Michael, F.J. The global population of mesoscale convective complexes. Q. J. R. Meteorol. Soc. 1997, 123, 389-405. [CrossRef]

30. Hou, A.Y.; Kakar, R.K.; Neeck, S.; Azarbarzin, A.A.; Kummerow, C.D.; Kojima, M.; Oki, R.; Nakamura, K.; Iguchi, T. The Global Precipitation Measurement Mission. Bull. Am. Meteorol. Soc. 2014, 95, 701-722. [CrossRef]

31. Hsu, K.; Gao, X.; Sorooshian, S.; Gupta, H.V. recipitation Estimation from Remotely Sensed Information Using Artificial Neural Networks. J. Appl. Meteorol. 1997, 36, 1176-1190. [CrossRef]

32. Kubota, T.; Shige, S.; Hashizume, H.; Aonashi, K.; Takahashi, N.; Seto, S.; Hirose, M.; Takayabu, Y.N.; Ushio, T.; Nakagawa, K. Global Precipitation Map Using Satellite-Borne Microwave Radiometers by the GSMaP Project: Production and Validation. IEEE Trans. Geosci. Remote Sens. 2007, 45, 2259-2275. [CrossRef]

33. Mega, T.; Ushio, T.; Kubota, T.; Kachi, M.; Aonashi, K.; Shige, S. Gauge Adjusted Global Satellite Mapping of Precipitation (GSMaP_Gauge). In XXXIth URSI General Assembly and Scientific Symposium (URSI GASS); IEEE: Beijing, China, 2014; pp. 1-4.

34. Rozante, J.R.; Moreira, D.S.; de Goncalves, L.G.G.; Vila, D.A. Combining TRMM and Surface Observations of Precipitation: Technique and Validation over South America. Weather Forecast. 2010, 25, 885-894. [CrossRef]

35. Reboita, M.S.; Gan, M.A.; da Rocha, R.P.; Ambrizzi, T. Regimes de precipitação na América do Sul: Uma revisão bibliográfica. Rev. Bras. Meteorol. 2010, 25, 185-204. [CrossRef] 
36. Velasco, I.; Fritsch, J.M. Mesoscale convective complexes in the Americas. J. Geophys. Res. 1987, $92,9591$. [CrossRef]

37. Quadro, M.F.L.; de Dias, M.A.F.; Herdies, D.L.; Gonçalves, L.G.G. de Análise climatológica da precipitação e do transporte de umidade na região da ZCAS através da nova geração de reanálises. Rev. Bras. Meteorol. 2012, 27, 152-162. [CrossRef]

38. Vera, C.; Baez, J.; Douglas, M.; Emmanuel, C.B.; Marengo, J.; Meitin, J.; Nicolini, M.; Nogues-Paegle, J.; Paegle, J.; Penalba, O.; et al. The South American Low-Level Jet Experiment. Bull. Am. Meteorol. Soc. 2006, 87, 63-78. [CrossRef]

39. Zhou, J.; Lau, K.-M. Does a Monsoon Climate Exist over South America? J. Clim. 1998, 11, $1020-1040$. [CrossRef]

40. Kousky, V.E. Alonso Gan M Upper tropospheric cyclonic vortices in the tropical South Atlantic. Tellus 1981, 33, 538-551. [CrossRef]

41. Kousky, V.E. Pentad outgoing longwave radiation climatology for the South American sector. Rev. Bras. Meteorol. 1988, 3, 217-231.

42. Cohen, J.C.P.; Silva Dias, M.A.F.; Nobre, C.A. Environmental Conditions Associated with Amazonian Squall Lines: A Case Study. Mon. Weather Rev. 1995, 123, 3163-3174. [CrossRef]

43. Shige, S.; Yamamoto, T.; Tsukiyama, T.; Kida, S.; Ashiwake, H.; Kubota, T.; Seto, S.; Aonashi, K.; Okamoto, K. The GSMaP Precipitation Retrieval Algorithm for Microwave Sounders-Part I: Over-Ocean Algorithm. IEEE Trans. Geosci. Remote Sens. 2009, 47, 3084-3097. [CrossRef]

44. Kachi, M.; Kubota, T.; Ushio, T.; Shige, S.; Kida, S.; Aonashi, K.; Okamoto, K.; Oki, R. Development and Utilization of "JAXA Global Rainfall Watch" System based on Combined Microwave and Infrared Radiometers Aboard Satellites. IEEJ Trans. Fundam. Mater. 2011, 131, 729-737. [CrossRef]

45. Ushio, T.; Sasashige, K.; Kubote, T.; Shige, S.; Okamoto, K.; Aonashi, K.; Inoue, T.; Tankahashi, N.; Iguchi, T.; Kachi, M. A Kalman Filter Approach to the Global Satellite Mapping of Precipitation (GSMaP) from Combined Passive Microwave and Infrared Radiometric Data. J. Meteorol. Soc. Jpn. 2009, 87A, 137-151. [CrossRef]

46. Wilks, D. Statistical Methods in the Atmospheric Sciences, 3rd ed.; Academic Press: Cambridge, MA, USA, $2011 ;$ p. 676.

47. Roebber, P.J. Visualizing Multiple Measures of Forecast Quality. Weather Forecast. 2009, 24, 601-608. [CrossRef]

48. Ning, S.; Song, F.; Udmale, P.; Jin, J.; Thapa, B.R.; Ishidaira, H. Error Analysis and Evaluation of the Latest GSMap and IMERG Precipitation Products over Eastern China. Adv. Meteorol. 2017, 2017, 1-16. [CrossRef] 